\title{
A fabricação da imagem pública dos reis mesopotâmicos: a divindade por trás do poder
}

\section{The making of the public image of the Mesopotamian kings: the divinity behind the power}

\section{La elaboración de la imagen pública de los reyes me- sopotámicos: la divinidad detrás del poder}

\author{
Luiz Alexandre Solano Rossi* \\ Submetido em: 28-6-2021 \\ Aceito em: 18-8-2021
}

* Pontifícia Universidade Católica do Paraná; UNINTER

Pós-doutor em História Antiga

E-mail: luizalexandrerossi@yahoo.com.br

\begin{abstract}
RESUMO
$\mathrm{Na}$ Mesopotâmia o rei e a divindade são realidades que se aproximam simbioticamente; terra e céu são realidades pensadas simultaneamente e, porque não dizer que a realidade terrena se apresenta como se fosse um reflexo da realidade celestial, ou seja, o que acontece no céu é reproduzido na terra. O rei, divinizado, além de seu corpo mortal, assume um corpo simbólico a partir do qual exercerá seu poder. De forma específica, na Assíria, a ideia de poder se encontra sempre próximo da convivência com as divindades. O rei é a própria imagem de um poder sacralizado e absoluto legitimado pela proteção divina. O rei e os deuses se encontram em permanente diálogo. Assim, o rei é hermeneuta da vontade dos deuses ao representar a realeza divina no plano terrestre.
\end{abstract}

Palavras-chave: Rei; deuses; Mesopotâmia; Assíria; poder.

\begin{abstract}
In Mesopotamia, the king and divinity are realities that are symbiotically close to each other; earth and heaven are realities that are thought of simultaneously and, why not say that the earthly reality is presented as if it were a reflection of the celestial reality, that is, what happens in heaven is reproduced on earth. The divinized king, besides his mortal body, assumes a symbolic body from which to exercise his power. Specifically, in Assyria, the idea of power is always close to the coexistence with divinities. The king is the very image of a sacralized and absolute power legitimated by divine protection. The king and the gods are in permanent dialogue. Thus, the king is a hermeneut of the gods' will by representing the divine kingship on the earthly plane.

Keywords: King; gods; Mesopotamia; Assyria; power.

\section{RESUMEN}

En Mesopotamia, el rey y la divinidad son realidades simbióticamente cercanas; la tierra y el cielo son realidades pensadas simultáneamente y, por qué no decirlo, la realidad terrenal se presenta como si fuera un reflejo de la realidad celeste, es decir, lo que ocurre en el cielo se reproduce en la tierra. El rey, divinizado, además de su cuerpo mortal, asume un cuerpo simbólico desde el que ejercerá su poder. En concreto, en Asiria, la idea de poder está siempre cerca de la convivencia con las divinidades. El rey es la imagen misma de un poder sacralizado y absoluto legitimado por la protección divina. El rey y los dioses están
\end{abstract}


en permanente diálogo. Así, el rey es una hermenéutica de la voluntad de los dioses al representar la realeza divina en el plano terrenal.

Palabras claves: Rey; dioses; Mesopotamia; Asiria; poder.

\section{Introdução}

Reis são fabricados e, portanto, existe por trás dele uma construção artificial que promove sua imagem pública. No antigo Oriente Próximo, mas especificamente na Assíria, objeto desse artigo, o rei é escolhido por uma graça divina e não por seus próprios méritos, devendo representá-lo na Terra, isto é, ele não é um representante, em primeiro plano, de seus súditos, mas de Deus. Por isso, o rei é divinizado, passando a ter, além de seu corpo humano mortal, um corpo simbólico e místico imortal, seu corpo político; e se apresentará como o pai da justiça que, significativamente quer dizer que sua vontade é a lei e, além disso, a terra é considerada seu patrimônio pessoal para fazer dela a extensão de seu reino e, por consequência, sendo seu patrimônio, fazer nela o que quiser.

A imagem do rei sagrado passaria exatamente pela perspectiva de se fabricar a figura do chamado "rei ideal". O ideal de rei foi concebido, por exemplo, pelos poetas de Sumer e de Acádia, que viveram aproximadamente durante os cinco séculos entre 2100 e 1600 a.C. Nos hinos reais que compunham a fim de glorificar o rei, os poetas usavam imagens extravagantes e figuras hiperbólicas. $\mathrm{Na}$ verdade, pouco contavam a respeito das verdadeiras características do rei e de suas obtenções históricas; revelavam, isso sim, o tipo ideal de rei que o povo de Sumer e da Acádia gostariam de possuir. Para os poetas o rei era dotado com uma grande sabedoria e com um profundo entendimento além de um físico proeminente e de uma coragem heroica. $\mathrm{O}$ rei Sulgi diz assim: "Semelhante ao meu heroísmo, semelhante ao meu poder, eu estou acompanhado pela sabedoria"; e ainda: "Eu sou aquele que governa as cidades com a boca semelhante às armas" (KRAMER, 1974, p. 164).

No repertório hínico dos poetas acima citados, todos os reis foram dotados com sabedoria por Enki, e pelo menos dois deles, Sulgi e Isme-Dagan tinham obtido sete sabedorias, ou seja, "todas" as sabedorias. Mas o ideal do rei conseguia ir um pouco mais longe quando os poetas afirmam que o rei era psicologicamente astuto e penetrante, isto é, ele podia dar grandes e eloquentes conselhos na assembleia; podia procurar e encontrar a palavra sábia e ainda discernir as palavras que estavam no coração a fim de determinar as palavras verdadeiras e as palavras falsas. E por que não falar do rei como aquele que possuía um grande amor pela música e pela poesia? Para os poetas, os reis conheciam e diligentemente praticavam ambas. Segundo 
Kramer (1974, p. 173-74), isso parece ser verdade pelo menos no caso do rei Sulgi, pois boa parte de dois hinos representam sua devoção à música. E ainda de acordo com o autor de um desses hinos, o rei tinha "o poder de um poeta" e compunha o hino como "uma glorificação de seu poder" e como um "poema de sua força".

\section{A manipulação do poder através da imagem real e da imagem sagrada}

A fabricação de uma imagem real pública proporciona ao rei um enorme controle e manipulação do poder. A criação dessa imagem real ilumina a relação entre aquele que exerce o poder e aqueles que por ele são governados.

Mais fascinante ainda é o estudo da propaganda do rei e das tentativas de moldar ou manipular a "opinião pública" - no sentido dos meios em que os significados servem para reforçar as relações de dominação. Afinal de contas, o uso da propaganda real por intermédio do Império tem como objetivo disseminar e estabelecer, através do sistema social, formas simbólicas através das quais a dinastia possa expressar seu direito de governar sobre o povo. Dessa forma, utilizo a expressão propaganda conforme a definição de Whitelam (1986, p. 166) quando diz que "a propaganda é definida como um processo pelo qual uma visão particular de mundo é disseminada para uma audiência específica".

E, de certa forma, a fabricação de uma imagem real designa um processo. De fato, um processo de fabricação de imagem. Nesse processo busca-se um parecer mais do que favorável; torna-se necessário aproximar do rei características que encarnem qualidades sagradas. Segundo Burke (1994, p. 23), um "Estado centralizado precisa de um símbolo de centralidade. O soberano e sua corte, frequentemente vistos como uma imagem do cosmos, são um centro sagrado ou exemplar do restante do Estado". Sendo assim a própria vida diária do rei deveria compor-se de ações não necessariamente recorrentes, mas completamente carregadas de um forte conteúdo simbólico, exatamente porque eram desempenhadas em público por um ator cuja pessoa era sagrada. Dessa forma, consequentemente, os objetos materiais mais intimamente associados ao rei também se tornavam sagrados, porque o representavam.

A fabricação da imagem do rei possui íntima relação com a mecânica do poder, seja ele político e ou econômico. É através desse tripé: poder, política e economia que poderemos, com mais clareza, interpretar e entender um determinado rei e também perceber que as relações de poder têm essencial- 
mente por base uma relação de força estabelecida. Existem duas maneiras para o Estado manter o controle do poder. O modo mais comum de se manter o controle do poder e, de ao mesmo tempo, legitimá-lo é através do uso da força; todavia, tal empreendimento é muito custoso para a vida do país. A segunda maneira, que é menos custosa e mais politicamente eficiente, envolve o uso de formas simbólicas, que temos chamado de "propaganda".

Certamente a característica mais importante daqueles que controlam o exercício do poder é a habilidade de manipular o poder e de convencer a população de que suas motivações são as mais corretas possíveis. Tal situação determina o sucesso ou o fracasso dos que governam. Segundo Withelam (1986, p. 168 - trad. nossa):

No antigo Oriente Próximo a visão de que o estado ou a cidade-estado disseminavam um método para se legitimar é frequentemente centrado sobre um membro da elite real, o rei, que era poderoso e rico e que possuía o direito de governar pela virtude de suas conexões divinas. Vários meios foram usados para expressar essa visão, incluindo moedas, selos, estelas, e monumentos arquitetônicos como palácios e templos.

Não se deve esquecer que o palácio e o templo são os mais importantes símbolos visuais do poder real e indicadores do centro do poder dentro de uma sociedade estratificada. Poderíamos dizer, de certa forma, que essas realidades simbólicas definiam o relacionamento entre o governador e os governados. Isso significa dizer que a partir dos círculos concêntricos do poder, todos aqueles que estão do lado de fora e, mais especificamente, além do portão, estão ausentes da área do poder real. Na arquitetura real o poder simbólico está intramuros ou ainda está limitado à área urbana. No entanto, templo e palácio, são símbolos acessíveis somente ao rei. O povo não tem qualquer tipo de acesso aos símbolos. Certamente que os mesmos, nas mãos do povo se transformariam em instrumentos de libertação e não de alienação. Ao negar a realidade simbólica aos seus súditos, o rei traz para si todas as prerrogativas reais e sacerdotais. Ele assume os espaços que controlam a vida e ditam as regras do quotidiano. A partir desse momento o povo vive à mercê de quem exerce o poder e a ele se submete. Talvez, por não conseguirem acesso aos símbolos, o próprio povo assuma a vida, comportamento e valores do rei como uma realidade inerente a ele mesmo. Como se dissessem: "se não podemos transitar livremente entre os símbolos do sagrado e do poder e, nem ao menos possuí-los, reverenciemos e sirvamos ao rei, única pessoa a nos representar". Sem dúvida que, nesse caso, o rei é espelho que reflete ao povo aquilo que ele jamais poderá ter ou ser. 
Whitelam ajuda-nos ao esclarecer que o templo providencia um local para um ritual central de legitimação da dinastia. O relacionamento sagrado do centro proporcionaria assim, uma legitimação simbólica para a elite real: "o templo funcionaria como uma casa do tesouro que nos leva à noção do rei como uma figura simbólica central, ou seja, o tesouro é o resultado dos presentes dados desde governadores e povos em todas as partes do mundo ao rei e seu deus ou os benefícios vindos do comércio internacional" (1986, p. 172).

A estabilidade da realidade existente depende desse jogo imposto pelo rei. Necessariamente, ao caminhar pelos espaços do sagrado e do político a realeza assume seu "verdadeiro" lugar: o centro do mundo. Tudo o mais gira ao seu redor e tudo fica na mais extrema dependência dele. O país e todos os seus súditos gravitam ao seu redor e a ele deviam a manutenção da ordem física, natural e sobrenatural.

\section{A importância do rei no antigo Oriente Próximo}

Entre os sumérios o chefe da cidade era ao mesmo tempo o representante de deus sobre a terra; possuía o título de chefe religioso e, por isso, presidia e participava na edificação dos templos; esforçava-se em toda a sua atividade civil e religiosa para trabalhar em colaboração estreita com os deuses. A finalidade era que tudo estivesse organizado e orientado para que o mundo constituísse um digno reflexo do mundo dos deuses e a própria vida familiar do soberano era concebida como paralela à da família divina.

A realeza hitita, por sua vez, como a maioria das concepções da realeza que dominava o antigo Oriente Próximo, considerava o rei como detentor de um poder especial procedente de sua particular relação com a esfera dos deuses; o rei é o sacerdote dos deuses. Uma oração de Muwatalli chama a atenção: “...deuses do país hitita, senhores de quem eu sou sacerdote, que me haveis concedido uma realeza ilimitada sobre o país hitita" (ELIADE, 1980, p. 121). Na mesma oração insiste-se na natureza especial que confere a realeza e que desliga, de certo modo, o rei da condição humana:

Deus da tormenta pihassassi, não sou mais um mortal. Todavia, meu pai foi sacerdote da deusa solar de Arinna e de todos os deuses. Meu pai me gerou, porém, o Senhor, deus da tormenta pihassassi, arrebatou-me de minha mãe e me criou. Fez-me sacerdote da deusa solar de Arinna e de todos os deuses. No país hitita, fez-me rei. (ELIADE, 1980, p. 235)

O rei, de fato, era considerado o intermediário entre os deuses e os homens. Sua presença era indispensável durante as grandes festas anuais e as obrigações religiosas superam as necessidades do político; a tradição religiosa 
que gravitava ao redor do rei era muito forte. Praticamente tudo era decidido a partir da relação deus-rei. Talvez seja por isso que a tradição insista no fato de que o rei, nomeado ou consagrado por um deus, quando seus país passava por algum distúrbio - fome, epidemia, peste - quase necessariamente isso se devia a uma falta cometida pelo próprio rei contra os deuses e estes se afastavam do rei, do país e dos seus habitantes, abandonando-os à morte.

Segundo Frankfort (1976, p. 253), "o habitante da Mesopotâmia não podia imaginar uma sociedade ordenada sem um rei". Todavia, nem sempre a realeza foi entendida como uma instituição permanente. A realeza possuía caráter transitório em sua origem e somente com o passar do tempo, é que a realeza foi se convertendo numa instituição permanente, como podemos subtrair de um texto de Frankfort:

A necessidade que padeciam os habitantes de uma planície aluvial de importar grandes quantidades de materiais brutos, tais como madeira, pedra e metais, impôs a obrigação de salvaguardar esses materiais. Daí que os reis eleitos ou certos dignatários que podiam exercer poderes próximos dos reais, se viram forçados a estar continuamente alertas e, em consequência, a realeza perdeu seu caráter temporal. (1976, p. 240).

De forma geral, poderíamos elencar as seguintes características que imbricam a figura do rei e a divindade numa notável simbiose:

1. A autoridade do rei provinha de sua eleição divina e, portanto, a realeza desce do céu.

2. O termo mesopotâmico mais antigo para "rei" expressa um ponto de vista comum até o final do império assírio: lugal que significa "grande homem". Segundo Frankfort (1976, p. 39), essa palavra pode ainda designar: "o amo de um escravo ou o proprietário de um campo, pelo que podemos deduzir que a comunidade se colocava totalmente nas mãos do seu governante".

3. O rei que governa a cidade é um grande proprietário. Bertman (2003, p. 63) ressalta a relação entre poder religioso, poder político e poder econômico:

Não obstante as propriedades de famílias ou indivíduos, as maiores parcelas de terra estavam sempre nas mãos dos sacerdotes (que eram os servos dos deuses) e dos reis (que eram os substitutos dos deuses na terra). Assim, aqueles que detinham a autoridade suprema também controlavam a maior parte da propriedade e da riqueza que ela produzia.

4. Exerce também a função de juiz supremo

5. É ao rei que compete construir e restaurar templos, manter os canais de irrigação e defender o país. 
6. O palácio, residência do rei, apresenta-se como um vasto complexo do mesmo tipo que o do templo, com a particularidade de o elemento militar desempenhar nele um papel essencial.

7. Como primeira figura do Estado, o rei concentra em suas mãos todos os poderes. É o chefe supremo dos exércitos e o responsável pela política externa. Controla ainda o conjunto da administração e o essencial do comércio internacional. Os seus primeiros domínios asseguram-lhe rendimentos importantes.

8. Para os babilônios "aquilo que está no alto" funda e justifica "o que está abaixo". O mundo terrestre encaixa-se no mundo celeste e isso proporciona um particular significado ao antropomorfismo divino. Porém, a característica prevalecente deste paralelismo é a existência de um elemento intermediário, espécie de prisma que projeta o céu entre os homens e reflete a terra aos olhos dos deuses: o monarca. Um tema corrente no primeiro milênio nos ensina assim: "no céu e sobre a terra, deus e o rei fazem rigorosamente o mesmo gesto. $\mathrm{O}$ que lá se ata, aqui também se ata”. A oração de Nabucodonosor II (605-562), dirigida a Shamash, é uma clara representação da relação entre o rei e a divindade na vida diária de um rei, conforme pode ser observado no livro organizado pela equipe "Cahiers Evangile":

Shamash, grande Senhor, quando entrares alegremente no templo de Ebabbar, tua casa brilhante, olhe cuidadosamente a obra de minhas mãos e que haja em seus lábios palavras em meu favor. Por tua firme ordem, que eu tenha uma idade prolongada, que tenha uma vida de dias longínquos e que meus anos de reinado sejam muitos, florescendo para sempre. Que um cetro justo, um bom pastoreio e um bastão real legítimo que proteja as pessoas, sejam o lote de minha realeza para sempre. Com tuas armas furiosas levantadas em batalha, que sejas a proteção do meu exército, oh Shamash. Responde-me corretamente no juízo e na adivinhação. Por tua palavra pura, que é insubstituível, que minhas armas sejam levantadas e afiadas, que derrubem as armas dos inimigos (1979, p. 37).

\section{Assíria: um caso de simbiose entre o rei e a divindade}

A Assíria se localiza especificamente na região da Mesopotâmia, expressão forjada pelos gregos, que significa "terra entre rios". O nome da capital era Assur, reconhecida como um dos principais centros políticos da época e também a primeira sede governamental da Assíria. O nome da importante capital é uma homenagem a sua principal divindade, o deus da guerra e da justiça que se chama Assur. O mundo assírio se apresenta, portanto, como uma simultaneidade de religião, política, ritual e belicismo que acabam por definir quem são bem como definir quem é o outro. 
Imperialismo, fenômeno tão antigo quanto o da civilização, pode ser entendido como a "política de um Estado que se propõe a estabelecer um controle para além de suas fronteiras sobre um povo que se nega a aceitar tal controle" (GARMUS, 1989, p. 7). É possível dizer que o conceito de "Império" nasce e se consolida ao se conjugar dois fatores: uma explícita busca pela totalidade, isto é, a inclusão de todo o mundo habitado em uma só conformação política, e uma conjunção de diferentes fatores de seu poder em um projeto único. E, nesse sentido, a Assíria foi um império. O mundo antigo o conheceu em todo seu poder por volta da segunda metade do século VIII sob Tiglat-Pileser III (745-727), um grande organizador e hábil militar. Após um período de fraqueza, Tiglate-Pileser III, o verdadeiro fundador do assim chamado império neoassírio, ascendeu ao trono assírio. De acordo com Garmus (1989, p. 11), estavam em conflito duas concepções de império, a tradicional, baseada na antiga realeza, e a nova, baseada na nobreza de mercadores. A Assíria precisava, segundo Herbert Donner (1997, p. 344), “de uma concepção clara e objetiva e de um homem que a soubesse interpretar e manejar soberanamente para aumentar o império". Foi Tiglat-Pileser III que assim o fez e realizou uma reforma administrativa que centralizou o poder assírio. Sua ambição era controlar as terras além do Eufrates por causa da madeira e minerais, mas, sobretudo, porque eram portas para o Egito, sudoeste da Ásia Menor, e para o comércio do Mediterrâneo.

De acordo com Gunneweg (2005, p. 183), ele tornou-se o verdadeiro fundador do império. Não se contentou com campanhas ocasionais sobre pequenos Estados para obrigá-los a pagarem tributos. Desejoso por estender seu território, provocou uma revolução na técnica da guerra: nos carros de combate substituiu as rodas de seis raios por outras de oito, mais resistentes; também passou a empregar cavalos de reposição, que permitiam maior rapidez e liberdade de movimentos; equipou os cavaleiros com armadura e a infantaria com botas. Suas campanhas eram subsidiadas por uma política que visava à submissão definitiva e completa das regiões conquistadas. É necessário interpretar a marcha triunfal do imperialismo assírio a partir de Tiglat-Pileser III sobre o transfundo de uma política expansionista bem pensada, de uma prática sistemática de avassalamento e de uma superioridade militar.

Suas campanhas não visavam apenas vincular pequenos Estados e exigir tributos numa relação de vassalagem, mas sim realizar a conquista permanente. Além de cobrar tributos, em caso de rebelião deportava os culpados e incorporava suas terras às províncias do império. Segundo Bright (2003, p. 328), três palavras descrevem as investidas da Assíria nesse período, "conquistar, ocupar, dominar". Tiglat-Pileser III desenvolveu um sistema de ani- 
quilação da autonomia política dos vassalos com o objetivo de incorporá-los na estrutura das províncias assírias. Com objetivo de dominar o território de acesso ao Egito, sua primeira campanha em 738 a.C. transformou a Síria e a Fenícia em vassalos. Em sua segunda campanha, em 734 a.C., Tiglat-Pileser vai até Gaza (Israel também é atingido). Nesta campanha anexou pequenas províncias como Dor, Meggido e Gileade. Israel ficou reduzido às montanhas de Efraim. A prática do imperialismo assírio era a de "movimentar os líderes" com a intenção de desmantelar a vida pública (PIXLEY, 1989, p. 63).

A forma com que a Assíria impunha sua cultura bélica sobre Estados menores além de violenta era bem estruturada e estava enraizada no próprio modelo de sociedade. A intervenção militar proporcionava condições para imposição de um modelo de economia, política, sociedade e religião. A submissão não acontecia apenas em um dos âmbitos. Os subordinados eram, em todos os âmbitos, obrigados a se submeter ao domínio assírio, ou seja, estavam sob a administração central, assim como as províncias, eram tributários, tinham as mesmas camadas sociais e eram súditos do deus Assur. Ademais, o militarismo estava vinculado com o fenômeno religioso, e os dois pertenciam ao embasamento ideológico. Assim sendo, segundo Ramírez (1991, p. 10), “o militarismo faz uso do fenômeno religioso para conseguir seus fins, também a religião, em determinadas circunstâncias, assume características militares". E para Rossi (2020, p. 70-71), o auxílio divino era constante e sempre certo no projeto expansionista dos reis assírios. Os próprios deuses participavam nas batalhas, caminhando à frente e garantindo a vitória. Numa palavra, os reis assírios sempre desfrutaram da proteção dos deuses em suas ações bélicas. Dessa forma, os deuses sempre puderam dispor da lealdade assíria para dar execução a uma guerra, o que sempre se revelaram dispostos.

A guerra feita pelo rei era ordenada pela divindade e, por conta disso, tratava-se de uma guerra onde a participação dos deuses era efetiva. Assim, os reis não lutavam sozinhos, mas com as poderosas armas de Assur e desfrutavam do apoio dos grande e terríveis deuses em suas campanhas. Assim, deve-se compreender a força bélica não somente como um mecanismo para desencorajar e esmagar revoltas ou para exercer domínio extraterritorial, mas, também como uma expressão simbólica, política e religiosa. Estamos, portanto, diante de uma narrativa teológica que proclamava que a Assíria havia sido escolhida pelos deuses para governar um império sem fim, ou seja, os quatro cantos da terra. Percebe-se, assim, que o império assume uma dimensão religiosa e reivindica, por causa disso, um sentido de transcendência, de onipotência que, por isso mesmo, dado seu caráter de onipotência, sempre será considerado uma ameaça final à liberdade humana. 
Palma (2002, p. 55-57) detalha a maneira pela qual a percepção da presença dos deuses no campo de batalha se apresenta:

Todos os grandes deuses mesopotâmicos se mostraram favoráveis a Adad-nirari I. Este favor dá a certeza da vitória, revela quem tem razão, e o rei sozinho vence todos. Onde está o seu exército? Não faz sentido falar dele; é a figura do rei que se evidencia e se enaltece; ele é o sujeito da gesta triunfal, porque auxiliado pelos grandes deuses. Lutou com as armas de Assur, logo, sua superioridade militar está assegurada. Foi com a ajuda dos deuses, dos grandes deuses, que Tiglat-Pileser I construiu o seu domínio, numa batalha sem tréguas que as divindades lhe ordenaram e na qual estiveram empenhadas por forma a garantir um total sucesso.

O rei, figura principal nessa organização de comando, apresentava-se como o próprio representante de sua divindade - o deus Assur. Assur é, portanto, o deus da nação assíria. De divindade local da cidade de mesmo nome, acompanhou a emergência e a expansão do poder e domínio assírios e, paralelamente, ascende a deus supremo na religião assíria: a sua ascensão caminhou ao lado dos grandes conquistadores assírios. Para trazer o mundo sob o domínio do deus Assur não exigia a aplicação do culto de Assur, mas submissão à soberania do seu representante e estar ciente de Assur (HOLLOWAY, 2002, p. 74). A percepção dos assírios é a de que cumprem uma designação e/ou missão divina, isto é, uma missão atribuída pelo próprio deus. Liverani (2016, p. 680) nos possibilita uma melhor compreensão:

No momento em que, no plano físico, os assírios realizam suas obras de conquista territorial, de submissão de outros povos à sua vontade, de centralização obrigada das forças de trabalho e de recursos econômicos, declaram que o que estão fazendo é uma obra de civilização necessária e meritória, de colonização do mundo, de unificação de todos sob o único poder legítimo, em nome dos deuses assírios, como conclusão da obra de criação e de ordenação cósmica iniciada pelos próprios deuses. Quando as fronteiras do império assírio coincidirem com os confins extremos do mundo, quando todos os recursos forem dirigidos para o centro, quando todos os homens forem submetidos à única realeza legítima, só então a criação se completará e o mundo será perfeito.

O rei, à frente de um imenso exército de funcionários civis e militares, exigia-lhe que prestassem contas da mesma forma que ele a Deus. O soberano assírio era o realizador, na primeira pessoa, das destruições e dos extermínios desejados pelos deuses. Segundo Rossi (2020, p. 56), foi sublinhado por diversas vezes que, diferentemente dos soberanos de vários povos, o rei assírio não se qualificava como "pastor do povo", mas sim como "vingador do deus Assur", como fúria devastadora, como férreo dono e senhor das gentes. A Assíria trazia arraigado uma concepção de universalidade interna na qual 
estava implícito todo o mundo destinado, por ordem divina, a pertencer-lhe, a estar submetido ao rei assírio, considerado vértice de todo poder na terra. A concentração de poder no "vértice" humano pode ser considerada a partir de seus muitos títulos:

O rei assírio é o vértice da pirâmide do poder. Todos os poderes convergem para uma identidade única - "rei grande", "rei dos reis", "governador dos governadores", "senhor dos senhores", "rei de todos os povos", "rei de todos os príncipes" - são títulos que conferem aos reis assírios um poder máximo e absoluto sobre outros detentores de poderes "pequenos". (PALMA, 2001, p. 43).

Os assírios desejavam ser lembrados como homens cruéis e queriam ser vistos com a marca da brutalidade e, por isso, consideravam-se o braço da potência destruidora que é o deus Assur - o Deus da guerra - e, consequentemente, se viam como a mais pura expressão terrena de duas outras terrificantes divindades, Ninurta e Adad, conhecidas pelo seu caráter altamente belicoso. O avanço inexorável do exército assírio significava para todas as pessoas o jugo impiedoso ou a destruição total. A Assíria não admitia aliados, porque só ela devia dominar em todo o mundo conhecido.

Pode-se dizer que a combinação de uma ideologia religiosa com a premissa de um governo centralista e enérgico lançou as bases do militarismo assírio. Nas palavras de Donner (1997, p. 338):

O rei, como mandatário do deus imperial Assur, estava à testa de um imenso exército de funcionários civis e militares, que eram obrigados a lhe prestar contas da mesma forma que ele a Deus. A isso somou-se, como condição prévia da política externa imperialista, a formação e a manutenção de um exército permanente de grande força combativa, com destacamentos de carros de guerra e, pela primeira vez, também com uma cavalaria, que podia entrar em combate com extrema rapidez e eficácia.

O âmbito ideológico da estrutura administrativa estava na religião e o rei estava no topo de toda a administração. Considerava-se o sacerdote de Assur e seu dever era ampliar os domínios de seu senhor. Em toda a sua extensão, a Assíria é culturalmente complexa e, por isso, refletir a respeito das dimensões político-religiosas separadamente em termos absolutos seria redutor. A separação do divino e mundano, sagrado e profano, segundo a compreensão moderna de laicização é inviável para a compreensão do imaginário dos antigos mesopotâmicos. Os reis deveriam prestar contas a Assur de suas ações e os povos deveriam reconhecer sua autoridade; por isso, segundo Garmus (1989, p. 17): 
(...) nenhum tratado de aliança, com exceção do feito com Babilônia, era feito em pé de igualdade. Assim, o domínio de Assur tornava-se praticamente extensível ao mundo, e seu representante na terra se achava investido de um poder de dominação universal. Uma das cláusulas desse tratado define a figura do soberano absoluto: Ele será vosso rei e vosso senhor. Ele pode abaixar o poderoso e elevar o fraco, condenar à morte quem o mereça e agraciar quem possa sê-lo. Ouvireis tudo o que ele disser e fareis tudo o que ele ordenar. Não induzireis nenhum outro rei, nenhum outro senhor contra ele.

A coesão do império era mantida pela religião. Todos que tivessem alguma função, seja administrativa, militar ou social, deveria jurar fidelidade ao rei diante das imagens do deus Assur. Tal atitude significava vingança em caso de violação. Rawlinson constata a intrínseca relação entre a divindade e a realeza:

Os reis assírios desde os primeiros tempos evidentemente consideravam Asshur como sua divindade tutelar especial. Eles usavam constantemente seu nome como um elemento em seus próprios títulos; eles o invocavam em todas as ocasiões que se referiam ao exercício de suas funções soberanas. As leis do império eram as leis de Assur, o tributo pago pelos reinos dependentes era o tributo de Assur. (Rawlinson apud HOLLOWAY, 2001, p. 25 - trad. nossa).

O papel religioso do rei é essencial para assegurar a manutenção de seu reinado. $\mathrm{Na}$ Assíria, quatro títulos são usados em relação ao rei em contextos específicos. Eles indicam os diferentes aspectos da posição do rei e mostram um modelo fundamental de relacionamento entre a comunidade, a divindade e os reis. Os títulos são assim conhecidos: issiak Assur; rubaum; waklum e belum. No entanto, o primeiro dos títulos é o que mais importa no contexto da pesquisa. O rei em sua performance como issiak Assur, "vicário de Assur" ou "vice-rei de Assur" funcionava como chefe sacerdotal da cidade e como o intermediário entre a divindade e a comunidade. Palma (2001, p. 34) faz uma importante observação:

O título de vice-rei de Assur encerra em si mesmo uma expressão político-religiosa definidora do exercício do poder que não se concebe sem referência à divindade: é óbvio que o primeiro título define especificamente o governante na sua relação face a Assur. O termo issiakum não pode estar sozinho, um homem não pode simplesmente ser issiakum sem a referência a Assur. No plano institucional o verdadeiro rei é Assur e quem exerce a realeza, em seu nome, junto da comunidade humana é o monarca terreno. O rei se dirige à divindade como "um servo aos seus senhores".

A consciência do rei pode ser constatada, por exemplo, nos "Anais de Senaqueribe" que expressam o vínculo de poder, de conquista e de religião no mandatário do país e recorda os poetas que citamos na introdução a este artigo: 
Senaqueribe, o grande rei, o poderoso rei, rei do universo, rei da Assíria, rei dos quatro cantos da terra; o sábio pastor, favorito dos grandes deuses, guardião do direito, amante da justiça; aquele que dá apoio e vem para ajudar o necessitado, que muda seus pensamentos para atos piedosos; perfeito herói; poderoso homem; o primeiro entre todos os príncipes; o deus Assur, a grande montanha, uma realeza inigualável me confiou, e acima de todos aqueles que moram em palácios, tornou poderosa minhas armas, toda a humanidade ele trouxe submissa aos meus pés. (LUCKENHILL, 2005, p. 23).

Há, segundo Holloway (2001, p. 83), provas substanciais de que os reis sargônidas, por exemplo, cultivaram uma imagem "profissional" de competência técnica e informativa. Em suas inscrições narrativas, os reis se descrevem como sábios, inteligentes, compreensivos, experientes, conhecedores, informados, circunspectos, amplos de compreensão e competentes. Sargão II se posiciona como "o mais competente dos príncipes", "o príncipe mais sábio do mundo". Assurbanipal amplifica o status tradicional do rei assírio como hierofante, chefe de culto executivo, ao professar ter dominado todas as artes dos escribas, incluindo as artes da adivinhação, os segredos do céu e da terra, a sabedoria de Shamash e Adad.

E, não menos importante, é o relato de Senaqueribe, em seus Anais, a respeito da importância de Nínive: "Naquela época, Nínive, a nobre metrópole, a amada de Ishtar, onde todos são lugares de encontro de deuses e deusas; a subestrutura eterna, o fundamento eterno; cujo plano tinha sido projetado desde o passado, e cuja estrutura tinha sido tornada bela junto com o firmamento dos céus" (LUCKENHILL, 2005, p. 94).

A análise de Liverani (2016, p. 678) a respeito da percepção da figura do rei e da divindade em ambiente de confronto bélico nos ajuda a compreender a força teológica e ou ideológica das narrativas religiosas:

Os assírios sentem-se únicos e seguros de sua superioridade tecnológica e moral, e do apoio divino. Os inimigos são muito numerosos, heterogêneos, e se organizam em coalizões buscando superar sua inferioridade qualitativa com uma superioridade quantitativa. Porém, no momento do confronto, são sempre vencidos, de tal forma que se pode dizer que nunca há uma verdadeira batalha, mas apenas um massacre e uma fuga. O fato é que o rei assírio tem um canal direto e legítimo de comunicação com a divindade, em particular com o deus Assur, enquanto os inimigos são indivíduos "sem deuses", ou que são abandonados por seus deuses, ou apoiados por deuses inferiores. Portanto, para os assírios, basta ter confiança em seu rei, e para o rei assírio basta ter confiança na divindade que, de fato, exorta: Vai, não temas, estarei do teu lado. 


\section{Considerações finais}

O rei é um agente necessário para estabelecer a ordem, estando, pois, entre a esfera física e transcendental é o ordenador do cosmos, a própria discussão em torno do termo Kittum (amplamente subjetivo), podendo significar algo que se aproxima de "estabilidade", "justiça" ou "equilíbrio", fomenta o destaque para compreender a importância da figura governamental, o provedor da harmonia social. O rei é, portanto, um fator de equilíbrio cósmico, atuando nas dimensões humanas e divinas da existência. É nesse quadro que se pode entender melhor a íntima relação entre o soberano e a justiça: a garantia do bom curso da natureza e do universo encontra seu equivalente, no plano social, na atuação do rei, pelo estabelecimento e manutenção das normas de conduta e das regras de convivência (REDE, 2009, p. 137). A percepção possível é a de que os reis assírios são apresentados como entidades amadas dos grandes deuses a quem obedecem. Dessa forma, a ideia de poder no imaginário assírio se encontra sempre próxima da convivência com as divindades. Para a nossa conclusão, Palma (2001, p. 38) esclarece:

O rei é a imagem de um poder legitimado pela proteção divina, logo, sacralizado, absoluto. O rei e os deuses estão em permanente diálogo, porquanto, o primeiro é intérprete da vontade dos segundos representando a realeza divina no plano terrestre, revelando a ação volitiva das divindades na história dos homens.

\section{Referências bibliográficas}

BERTMAN, Stephen. Handbook to life in the ancient Mesopotamia. New York: Oxford University Press, 2005.

BRIGHT, John. História de Israel. São Paulo: Paulus, 2003.

BURKE, Peter. A fabricação do rei. São Paulo: Zahar, 1994.

DONNER, Herbert. História de Israel. Vol. 2. Vozes: Petrópolis, 1997.

EQUIPO Cahiers Evangile (org.). Oraciones del antiguo Oriente. Navarra: Verbo Divino, 1979. FRANKFORT, H. Reyes y dioses. Revista de Occidente, Madrid, 1976.

GARMUS, Ludovico. O Imperialismo: estrutura de dominação. Ribla: Revista de interpretação Bíblica Latino-Americana, São Paulo, n. 3, p. 7-20, 1989.

GUNNEWEG, Antonius H. J. Teologia bíblica do Antigo Testamento: uma história da religião de Israel na perspectiva bíblico-teológica. São Paulo: Teológica; Loyola, 2005.

HOLLOWAY, Steven W. Assur is King! Assur is King!: religion in the exercise of power in the Neo-Assyrian Empire. Leiden: Brill, 2001.

KRAMER, S.N. Kingship in Sumer and Akkad: the ideal king. In: GARELLI, P. (ed.). Le palais et la royauté. Paris: Librairie Orientaliste Paul Geuthner, 1974, p.163-176. 
LIVERANI, Mario. Antigo Oriente: história, sociedade e economia. São Paulo: Edusp, 2016.

LUCKENHILL, Daniel D. The Annals of Sennacherib. Eugene, OR: Wipf and Stock, 2005.

PALMA, Maria de Lourdes. Poder e imagem. A idealização do rei na historiografia assíria: de Samsi-Adad I a Tiglat-pileser. Cascais: Patrimonia, 2021.

PIXLEY, J. História de Israel a partir dos pobres. Petrópolis: Vozes, 1989.

RAMIREZ, Dagoberto. Militarismo y religion en el pueblo. Ribla: Revista de Interpretacion Biblica Latino-Americana, Santiago de Chile, n. 8, p. 7-13, 1991.

REDE, M. O "rei de justiça": soberania e ordenamento na antiga Mesopotâmia. Phoînix, Rio de Janeiro, v. 15, n. 1, p. 135-146, 2009.

ROSSI, Luiz Alexandre S. A importância da cidade para a realeza. Estudos Bíblicos, Petrópolis, n. 36, p. 9-15, 1992.

ROSSI, Luiz Alexandre S. Cultura militar e de violência no mundo antigo. São Paulo: Recriar, 2020.

WHITELAM, Keith W. The symbols of power. Biblical Archaeologist, Chicago, n. 49, n. 3, p. 166-173, 1986. 